\title{
Aorta Calcification Increases the Risk of Anastomotic Leakage After Gastrectomy in Gastric Cancer Patients
}

\author{
Wei Tao (i)* \\ Yu-Xi Cheng (1D* \\ Ying-Ying Zou \\ Dong Peng (D) \\ Wei Zhang
}

Department of Gastrointestinal Surgery, The First Affiliated Hospital of Chongqing Medical University, Chongqing, 400016,

People's Republic of China

*These authors contributed equally to this work
Correspondence: Dong Peng

Department of Gastrointestinal Surgery,

The First Affiliated Hospital of Chongqing

Medical University, Chongqing, 400016,

People's Republic of China

Tel +86-13370754855

Email carry_dong@I26.com
Purpose: The purpose of the present study was to evaluate whether vascular calcification is a risk factor for anastomotic leakage after gastrectomy in gastric cancer patients.

Methods: Patients with confirmed gastric cancer were collected from the database of a single clinical center from January 2013 to January 2019. The calcification score and anastomotic leakage were recorded, and predictors of anastomotic leakage were analyzed.

Results: A total of 856 patients were included in this study; 818 patients had no anastomotic leakage, and 38 patients had anastomotic leakage. The ratio of hypertension status $(p=0.011)$, open gastrectomy $(p=0.012)$, postoperative length of stay $(p=0.000)$, aorta calcification score $(p=0.000)$ and celiac axis calcification $(p=0.000)$ were higher in the anastomotic leakage group than in the nonanastomotic leakage group. In multivariate analysis, aorta calcification $(\mathrm{p}=0.029$, odds ratio $=2.425,95 \% \mathrm{CI}=1.095-5.491)$ was an independent predictor of the anastomotic leakage.

Conclusion: Aorta calcification is an independent risk factor for anastomotic leakage after gastrectomy in gastric cancer patients.

Keywords: calcification, leakage, gastrectomy, gastric cancer

\section{Introduction}

Gastric cancer is the fifth most common malignant tumor and the third-leading cause of cancer-related death in the world. ${ }^{1}$ There are nearly one million new cases of gastric cancer each year in the world, of which nearly $50 \%$ occur in China. ${ }^{2}$ Radical gastrectomy plays an important role in the treatment of gastric cancer in resectable patients, ${ }^{3,4}$ yet complications after gastrectomy can affect the quality of life and even overall survival. ${ }^{5-7}$

Improvements in surgical techniques and perioperative management were attributed to a reduction in mortality after radical gastrectomy for gastric cancer; ${ }^{8}$ nevertheless, anastomotic leakage is still relatively common. Anastomotic leakage is one of the most serious postoperative complications, and it has been reported that the incidence of anastomotic leakage is $0-17 \% .{ }^{8-10}$ Anastomotic leakage could lead to a reduced quality of life, longer hospital stays and increased costs and mortality, ${ }^{11}$ and furthermore, it had a negative impact on the long-term outcomes. $^{5,12}$

Vascular calcification has been implicated as an independent risk factor for anastomotic leakage after esophageal and colorectal cancer surgery. ${ }^{13,14}$ Vascular 
calcification might affect the blood supply of the anastomosis, $^{13}$ thus leading to anastomotic leakage. To our knowledge, there is no previous research related to vascular calcification and anastomotic leakage in gastric cancer in previously published studies. Therefore, the purpose of the present study was to evaluate whether vascular calcification is a risk factor for anastomotic leakage after gastrectomy in gastric cancer patients.

\section{Materials and Methods}

\section{Patients}

Patients with confirmed gastric cancer were collected from the database of a single clinical center from January 2013 to January 2019. This study was conducted in accordance with the World Medical Association Declaration of Helsinki, and ethical approval from the institutional review board was obtained (2021-021). A total of 1348 patients were collected from the database. Patients were included according to the following criteria: 1) patients who underwent gastrectomy + D2 lymph node dissection; and 2) patients were confirmed to have gastric cancer by pathology after gastrectomy. Finally, 1008 patients were included. Patients were excluded according to the following criteria: 1) incomplete medical record data $(\mathrm{n}=63)$; 2) incomplete preoperative computed tomography (CT) data ( $\mathrm{n}=71)$; and 3) palliative radical resection of gastric cancer $(n=18)$. In total, 856 patients were included in this study. The inclusion and exclusion criteria of patients with gastric cancer are shown in Figure 1.

\section{Surgery}

All patients included in this study underwent gastrectomy, and they were operated on by two surgeons with more than 10 years of surgical experience on the same team. The scope of lymph node dissection followed the Japanese gastric cancer treatment guidelines. ${ }^{15}$

\section{Medical Records Collections}

Baseline information, including sex, age, body mass index (BMI), the American Society of Anesthesiologists (ASA), chronic obstructive pulmonary disease (COPD), diabetes mellitus, smoking, drinking, coronary artery disease, hypertension, renal insufficiency, peripheral vascular disease and calcification score, was recorded. Surgical information was collected, including surgical approach, surgical procedure, transfusion, operation time, estimated blood loss, retrieved lymph nodes and type of anastomosis. Postoperative information, such as pathological TNM stage, anastomotic leakage and postoperative hospital stay, were included as well.

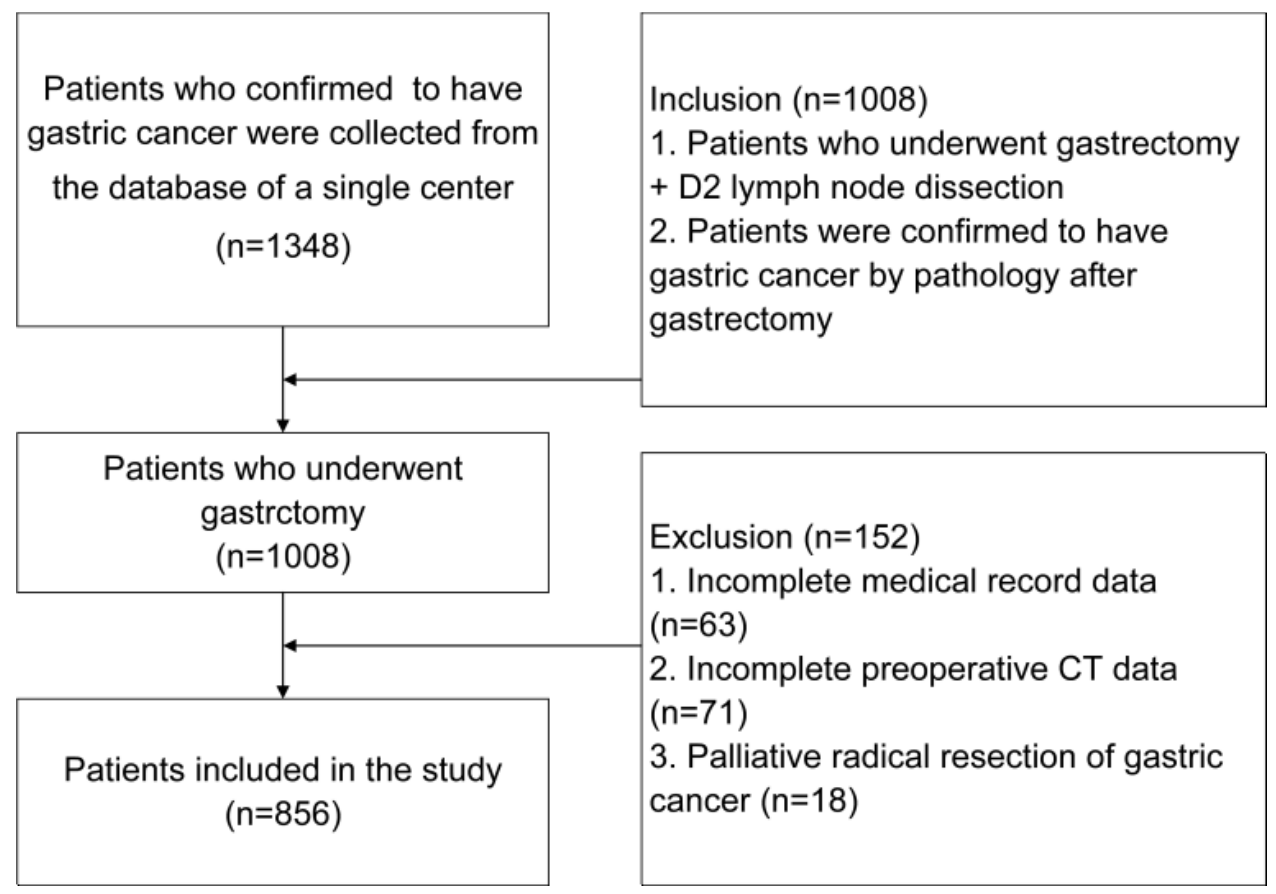

Figure I Inclusion criteria and exclusion criteria of patients who underwent gastrectomy. 


\section{CT Image Data}

All patients underwent a chest and abdomen CT examination within 14 days before the operation. The following equipment parameters were adopted: the tube current was $150 \mathrm{~mA}$; the tube voltage was $120 \mathrm{kVp}$; the section thickness was $5 \mathrm{~mm}$; and the section interval was $5 \mathrm{~mm}$. A 64 multidetector scanner (LightSpeed VCT; GE Healthcare, Waukesha, WI, USA) was used for CT scanning. The scanning ranged from the top of the chest to the bottom of the abdomen. An enhanced image was obtained after intravenous injection of $80-90 \mathrm{~mL}$ of nonionic contrast agent $(320 \mathrm{mg} / \mathrm{mL}$; iopamidol, Shanghai Braco Sinus Pharmaceutical Co., Ltd., Shanghai, China) at an injection rate of $3.0 \mathrm{~mL} / \mathrm{s}$ using a $50 \mathrm{~mL}$ saline tracker. The contrast agent-enhanced CT images were obtained 35 and 120 seconds after the injection of the contrast agent in the arterial phase and the equilibrium phase, respectively. CT images were independently measured by two physicians who were blinded to the patient's medical records, and any disagreements were resolved by consensus or in consultation with a senior physician.

\section{Definition}

The calcification score was modified according to previous studies. ${ }^{13}$ We calculated four arteries: the aortic artery (descending part of the thoracic aorta and abdominal part of the aorta above the celiac level), celiac axis artery, left postceliac arteries (splenic artery and left gastroepiploic artery) and right postceliac arteries (common hepatic artery, gastroduodenal artery and right gastroepiploic artery). The classification of scores is shown in Table 1 and Figure 2.

Upper gastrointestinal endoscopy and computed tomography were performed when a postoperative anastomotic leakage was clinically suspected based on a patient's symptoms or physical examination findings. All anastomotic leakage of Clavien-Dindo grade III or IV occurring within 90 days after the operation was defined as a postoperative anastomotic leakage. ${ }^{16,17}$

\section{Statistical Analysis}

Continuous variables, including age, BMI, operation time, estimated blood loss, retrieved lymph nodes and postoperative hospital stay, were calculated by the mean and standard deviation. Independent-sample t-tests were used to compare continuous variables between the anastomotic leakage group and the nonanastomotic leakage group. The
Table I Definitions of Arterial Calcification on Preoperative CT Images

\begin{tabular}{|c|c|c|c|}
\hline Artery & $\begin{array}{l}\text { Score } \\
0\end{array}$ & Score I & Score 2 \\
\hline Aorta* & Absent & $\begin{array}{l}\text { Minor calcifications: } \\
\leq 9 \text { foci and } \leq 3 \text { foci } \\
\text { extending over } \geq 3 \\
\text { sections }\end{array}$ & $\begin{array}{l}\text { Major calcifications: } \\
>9 \text { foci and }>3 \text { foci } \\
\text { extending over } \geq 3 \\
\text { sections }\end{array}$ \\
\hline Celiac axis & Absent & $\begin{array}{l}\text { Minor calcifications: } \\
\text { Extending over }<3 \\
\text { sections or MCSD } \\
\text { of single focus } \leq \\
10 \mathrm{~mm}\end{array}$ & $\begin{array}{l}\text { Major calcifications: } \\
\text { Extending over } \geq 3 \\
\text { sections and MCSD } \\
\text { of single focus } \geq \\
10 \mathrm{~mm} \text { or involving } \\
\text { both the proximal } \\
\text { (aortoceliac) and } \\
\text { distal (hepatosplenic } \\
\text { bifurcation) parts }\end{array}$ \\
\hline $\begin{array}{l}\text { Left } \\
\text { postceliac } \\
\text { arteries† }\end{array}$ & Absent & $\geq$ I calcification & Not applicable \\
\hline $\begin{array}{l}\text { Right } \\
\text { postceliac } \\
\text { arteriesł }\end{array}$ & Absent & $\geq$ I calcification & Not applicable \\
\hline
\end{tabular}

Notes: *Aorta defined as descending part of thoracic aorta and abdominal part of aorta above celiac level; $\dagger$ right postceliac arteries defined as common hepatic artery, gastroduodenal artery, and right gastroepiploic artery; $¥$ left postceliac arteries defined as splenic artery and left gastroepiploic artery; MCSD, maximum cross-sectional diameter. Table was adapted with permission from van Rossum PS, Haverkamp L, Verkooijen HM et al Calcification of arteries supplying the gastric tube: a new risk factor for anastomotic leakage after esophageal surgery. Radiology. 2015; 274(I): $124-132 . .^{13}$

$\chi^{2}$ statistic or the Fisher's exact test was used to compare other parameters between the two groups. Multivariate analysis was used to identify predictors of anastomotic leakage. Data were analyzed using SPSS (version 20.0) statistical software. A bilateral $\mathrm{p}$ value of $<0.05$ was considered statistically significant.

\section{Results}

A total of 856 patients were included in this study: 818 patients without anastomotic leakage and 38 patients with anastomotic leakage. Baseline characteristics, surgical information and calcification scores were compared between the anastomotic leakage group and the nonanastomotic leakage group.

\section{Baseline Characteristics}

Sex, age, BMI, ASA, COPD, diabetes mellitus, smoking, drinking, coronary artery disease, hypertension, renal 


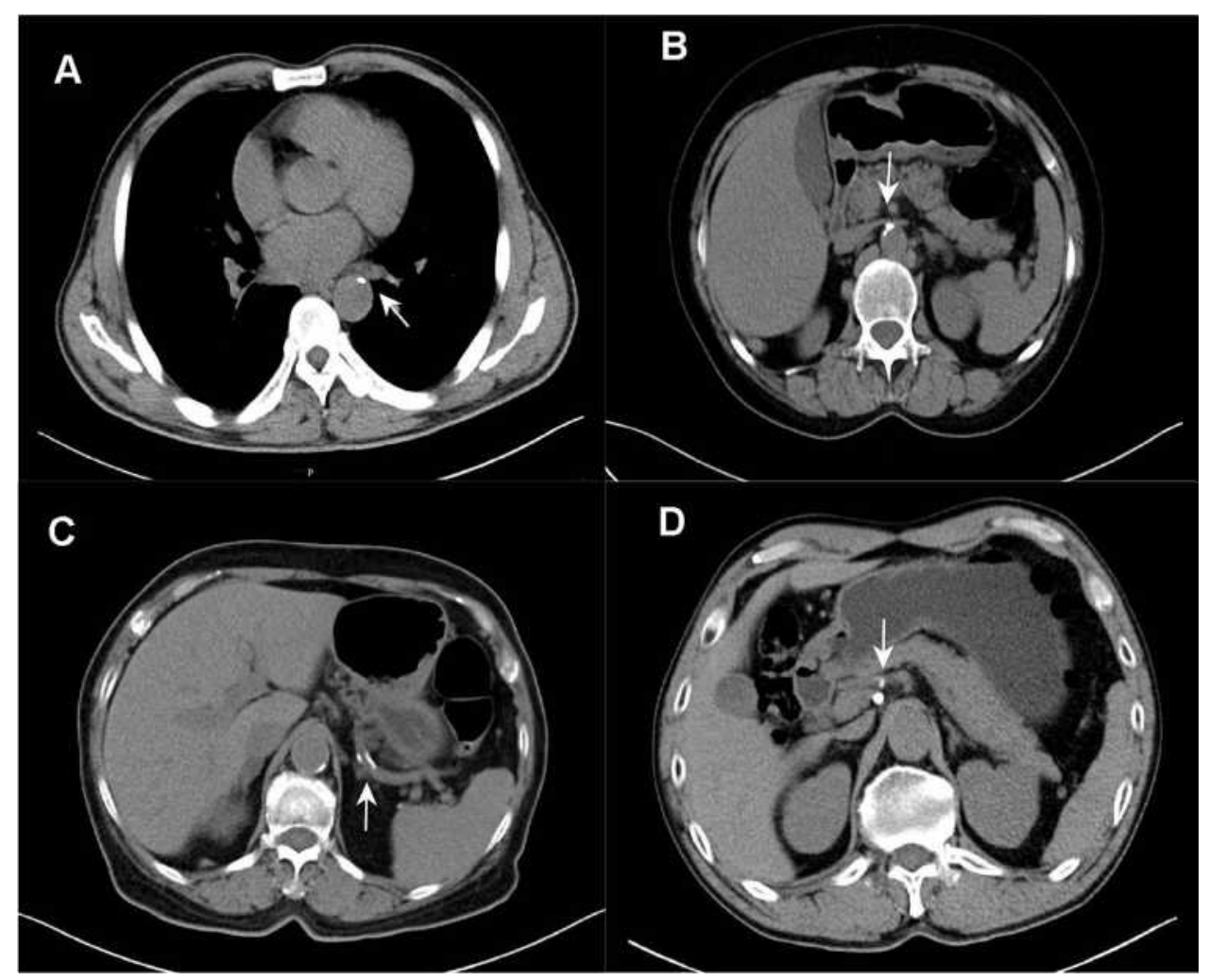

Figure 2 Examples of calcification on preoperative CT images in patients with gastric cancer. (A) Image showing the descending aorta with a plaque and calcified foci (arrow). (B) Image showing calcification of the celiac axis (arrow). (C) Image showing calcification of the splenic artery (arrow). (D) Image showing calcification of the common hepatic artery (arrow). A calcification score of I was assigned to the above four images.

insufficiency and peripheral vascular disease were collected, and the ratio of hypertension status was found to be higher in the anastomotic leakage group (28.9\%) than in the nonanastomotic leakage group $(12.5 \%)(\mathrm{p}=0.011)$. However, there was no statistically significant difference between the two groups in terms of any other baseline parameters (Table 2).

\section{Surgical Information}

We retrospectively collected the surgical information of the 856 patients. No statistically significant difference was found in the surgical procedure, combined organ resection, operation time, estimated blood loss, transfusion, retrieved lymph nodes, type of anastomosis or TNM stage ( $p>0.05)$. The ratio of open gastrectomy was $15.8 \%$ in the anastomotic leakage group and $4.8 \%$ in the nonanastomotic leakage group, which had statistically significantly higher anastomotic leakage rates than those treated with a laparoscopic gastrectomy $(\mathrm{p}=0.012)$. The anastomotic leakage group $(27.4 \pm 17.0$ days $)$ had a longer postoperative length of stay than the nonanastomotic leakage group $(11.4 \pm 5.4$ days) $(\mathrm{p}=0.000)$ (Table 3$)$.

\section{Calcification Score of Patients with/ without Anastomotic Leakage}

Calcification was calculated between the anastomotic leakage group and the nonanastomotic leakage group. The ratio of the aorta score 0 in the anastomotic leakage group was $42.1 \%$ versus $68.3 \%$ in the nonanastomotic leakage group, and the ratio of the celiac axis score 0 in the anastomotic leakage group was $68.4 \%$ versus $81.2 \%$ in the nonanastomotic leakage group. The aorta calcification $(\mathrm{p}=0.000)$ and celiac axis calcification $(\mathrm{p}=0.000)$ scores were higher in the anastomotic leakage group than in the nonanastomotic leakage group. However, there was no statistically significant difference between the two groups in terms of the left or right postceliac artery calcification score $(\mathrm{p}>0.05)$ (Table 4).

\section{Multivariate Logistic Regression Analysis Revealed Independent Factors Associated with Anastomotic Leakage}

Multivariate analysis was used to identify predictors of anastomotic leakage. In multivariate analysis, there were 
Table 2 Baseline Characteristics

\begin{tabular}{|c|c|c|c|}
\hline Characteristics & Anastomotic Leakage $(n=38)$ & Nonanastomotic Leakage $(n=8 \mid 8)$ & $P$ value \\
\hline Sex & & & 0.537 \\
\hline Male & 30 & 601 & \\
\hline Female & 8 & 217 & \\
\hline Age (year) & $62.6 \pm 9.8$ & $59.2 \pm 10.7$ & 0.053 \\
\hline BMI $\left(\mathrm{kg} / \mathrm{m}^{2}\right)$ & $23.0 \pm 3.7$ & $22.2 \pm 3.1$ & 0.114 \\
\hline ASA & & & 0.343 \\
\hline 1 & 32 & 677 & \\
\hline 2 & 6 & 102 & \\
\hline 3 & 0 & 39 & \\
\hline COPD & & & 1.000 \\
\hline Yes & 0 & 17 & \\
\hline No & 38 & 801 & \\
\hline Diabetes mellitus & & & 1.000 \\
\hline Yes & 2 & 45 & \\
\hline No & 36 & 773 & \\
\hline Smoking & & & 0.512 \\
\hline Yes & 22 & 427 & \\
\hline No & 16 & 391 & \\
\hline Drinking & & & 0.867 \\
\hline Yes & 21 & 469 & \\
\hline No & 17 & 349 & \\
\hline Coronary artery disease & & & 0.356 \\
\hline Yes & 2 & 26 & \\
\hline No & 36 & 792 & \\
\hline Hypertension & & & $0.011 *$ \\
\hline Yes & 11 & 102 & \\
\hline No & 27 & 716 & \\
\hline Renal insufficiency & & & 1.000 \\
\hline Yes & 0 & 4 & \\
\hline No & 38 & 814 & \\
\hline Peripheral vascular disease & & & 1.000 \\
\hline Yes & 0 & 9 & \\
\hline No & 38 & 809 & \\
\hline
\end{tabular}

Notes: Variables are expressed as the mean $\pm \mathrm{SD}$, *P-value $<0.05$.

Abbreviations: BMI, body mass index; ASA, the American Society of Anesthesiologists; COPD, chronic obstructive pulmonary disease.

no statistically significant differences in terms of age, BMI, surgical approach, hypertension or celiac axis calcification $(\mathrm{p}>0.05)$. Aorta calcification $(\mathrm{p}=0.029$, odds ratio $=2.425,95 \% \mathrm{CI}=1.095-5.491)$ was the only predictor of the anastomotic leakage (Table 5).

\section{Discussion}

In this study, the rate of hypertension, open gastrectomy, postoperative length of stay, aortic calcification score and celiac axis calcification score were higher in the anastomotic leakage group than in the nonanastomotic leakage group. In multivariate analysis, aortic calcification was an independent predictor of the anastomotic leakage.

To our knowledge, this is the first study to analyze the relationship between aortic calcification and anastomotic leakage after gastrectomy in patients with gastric cancer.

Anastomotic leakage is a serious complication after gastrectomy in patients with gastric cancer. With the 
Table 3 Surgical Information

\begin{tabular}{|c|c|c|c|}
\hline Characteristics & Anastomotic Leakage $(n=38)$ & Nonanastomotic Leakage $(n=8 \mid 8)$ & $P$ value \\
\hline Approach & & & $0.012 *$ \\
\hline Open & 6 & 39 & \\
\hline Laparoscopic & 32 & 779 & \\
\hline Procedure & & & 0.523 \\
\hline Total gastrectomy & 8 & 210 & \\
\hline Subtotal gastrectomy & 30 & 608 & \\
\hline Combined organ resection & & & 1.000 \\
\hline Yes & 0 & 20 & \\
\hline No & 38 & 798 & \\
\hline Operation time (minutes) & $210.3 \pm 65.3$ & $219.5 \pm 64.0$ & 0.387 \\
\hline Estimated blood loss (mL) & $123.2 \pm 89.9$ & $167.0 \pm 377.2$ & 0.475 \\
\hline Transfusion & & & 0.765 \\
\hline Yes & 2 & 76 & \\
\hline No & 36 & 742 & \\
\hline Retrieved lymph nodes & $22.3 \pm 9.7$ & $22.1 \pm 9.6$ & 0.853 \\
\hline Type of anastomosis & & & 0.321 \\
\hline B-I & 22 & 374 & \\
\hline B-II & 6 & 187 & \\
\hline$R-Y$ & 10 & 257 & \\
\hline TNM stage & & & 0.518 \\
\hline I & 15 & 240 & \\
\hline II & 5 & 144 & \\
\hline III & 18 & 424 & \\
\hline IV & 0 & 10 & \\
\hline Postoperative length of stay (day) & $27.4 \pm 17.0$ & $1 \mathrm{I} .4 \pm 5.4$ & $0.000 *$ \\
\hline
\end{tabular}

Notes: Variables are expressed as the mean $\pm \mathrm{SD}$, *P-value $<0.05$.

Abbreviations: B-I, Billroth I reconstruction; B-II, Billroth II reconstruction; R-Y, Roux-en-Y reconstruction; TNM, tumor-node-metastasis.

application of new surgical equipment and improvements in perioperative management, the incidence of complications has been reduced; ${ }^{18}$ however, anastomotic leakage after gastrectomy for gastric cancer is still an important problem. $^{19}$

Anastomotic leakage is also an important cause of postoperative abdominal infections, abscesses, abdominal bleeding and mortality. ${ }^{20}$ Improper management of anastomotic leakage might increase the risk of death, prolong hospitalization, increase hospitalization costs and even affect long-term survival. ${ }^{21}$ According to previous reports, there were several risk factors related to anastomotic leakage, including age, sex, smoking, malnutrition, operation time, tumor location, tumor stage, diabetes, and renal failure. $^{22,23}$ However, in the present study, despite the baseline information and surgical information, aorta calcification is an independent risk factor for anastomotic leakage.

The scoring system for calcification evaluated in this study was modified according to previous studies. Previous studies demonstrated that aortic calcification was an independent risk factor for esophageal and rectal cancer surgery. In this study, we found that aorta calcification was an independent risk factor for anastomotic leakage, but celiac axis calcification, left postceliac artery calcification and right postceliac artery calcification were not independent risk factors. Our findings indicated that aortic calcification rather than calcification of smaller blood vessels (celiac axis calcification, left postceliac artery and right postceliac artery calcification) significantly 
Table 4 Calcification Score of Patients with/without Anastomotic Leakage

\begin{tabular}{|c|c|c|c|}
\hline Artery & $\begin{array}{l}\text { Anastomotic } \\
\text { Leakage }(n=38)\end{array}$ & $\begin{array}{l}\text { Nonanastomotic } \\
\text { Leakage }(n=8 \mid 8)\end{array}$ & $P$ value \\
\hline $\begin{array}{c}\text { Aorta } \\
0 \\
1 \\
2\end{array}$ & $\begin{array}{l}16 \\
19 \\
3\end{array}$ & $\begin{array}{l}559 \\
182 \\
77\end{array}$ & $0.000 *$ \\
\hline $\begin{array}{l}\text { Celiac axis } \\
0 \\
1 \\
2\end{array}$ & $\begin{array}{l}26 \\
12 \\
0\end{array}$ & $\begin{array}{l}664 \\
154 \\
0\end{array}$ & $0.000 *$ \\
\hline $\begin{array}{l}\text { Left } \\
\text { postceliac } \\
\text { arteries } \\
0 \\
1\end{array}$ & $\begin{array}{l}37 \\
1\end{array}$ & $\begin{array}{l}802 \\
16\end{array}$ & $0.54 I$ \\
\hline $\begin{array}{l}\text { Right } \\
\text { postceliac } \\
\text { arteries } \\
0 \\
\text { I }\end{array}$ & $\begin{array}{l}37 \\
1\end{array}$ & $\begin{array}{l}807 \\
11\end{array}$ & 0.422 \\
\hline
\end{tabular}

Note: *P-value $<0.05$.

increased the risk of anastomotic leakage, which suggested that generalized vascular disease was more likely to contribute to the risk of anastomotic leakage rather than local vascular disease.

Aortic calcification is associated with many typical cardiovascular risk factors, and these factors, including age, diabetes, peripheral vascular disease and renal insufficiency, are also related to anastomotic leakage. ${ }^{22}$ In the current study, however, these cardiovascular complications were not significantly related to anastomotic leakage. Therefore, aortic calcification might help to identify high-

Table 5 Multivariate Logistic Regression Analysis Revealed Independent Factors Associated with Anastomotic Leakage

\begin{tabular}{|l|l|l|l|}
\hline Variable & OR & $\mathbf{9 5 \% ~ C I ~}$ & P value \\
\hline Aorta calcification (I and 2 VS 0) & 2.425 & $1.095-5.49 I$ & $0.029 *$ \\
Celiac axis calcification (I VS 0) & 1.024 & $0.443-2.365$ & 0.956 \\
Hypertension (yes VS no) & $1.5 I I$ & $0.657-3.476$ & 0.331 \\
Surgical approach (open VS & 2.672 & $0.985-7.244$ & 0.053 \\
laparoscopic) & & & \\
Age & 1.005 & $0.968-1.043$ & 0.799 \\
BMI & 1.075 & $0.97 I-I .190$ & 0.166 \\
\hline
\end{tabular}

Note: ${ }^{* P}$-value $<0.05$. risk patients who have not been diagnosed with these typical cardiovascular risk factors. ${ }^{24,25}$

Theoretically, adequate visceral blood perfusion is essential for the safe healing of anastomosis. ${ }^{26}$ A reduction in visceral blood perfusion might lead to ischemia of the anastomosis, delayed healing and anastomotic leakage. Surgeons usually confirm the anastomosis by examining the intestinal color. Good peristalsis, the presence of intestinal wall bleeding and vascular pulsation during the reconstruction process might represent adequate visceral blood perfusion. However, a study suggested that the intraoperative empirical evaluation by surgeons was relatively subjective and unreliable because of a low sensitivity and specificity. ${ }^{27}$ To evaluate intraoperative visceral perfusion, microperfusion evaluation techniques such as laser Doppler flowmetry, CT angiography of the abdomen or indocyanine green fluorescence angiography are necessary. ${ }^{28}$ Perioperative interventions, including physical therapy to increase cardiopulmonary function, enhanced nutritional supplementation to improve nutritional status, smoking cessation, reduced blood sugar fluctuations and blood pressure control, might be necessary to reduce the risk of anastomotic leakage in high-risk patients.

Therefore, for patients with high-risk factors, including advanced age, diabetes mellitus, hypertension, high blood lipids, aortic stenosis, aortic atherosclerosis and peripheral vascular disease, surgeons should pay more attention to artery calcification from preoperative $\mathrm{CT}$ and be alert to postoperative complications related to anastomotic leakage.

This study has certain limitations. First, this was a retrospective study, with a relatively small sample size (38 patients) of anastomotic leakage patients. Second, aortic calcification may be a marker reflecting atherosclerosis and impaired perfusion, and there are more specific methods to determine the degree of vascular disease and local perfusion, such as Doppler flowmetry or CT angiography. Therefore, large samples, multicenter clinical trials, and more specific local perfusion methods are required for further investigation.

\section{Conclusion}

The aorta calcification and celiac axis calcification scores were higher in the anastomotic leakage group than in the nonanastomotic leakage group. Aorta calcification is an independent risk factor for the anastomotic leakage after gastrectomy in gastric cancer patients. 


\section{Data Sharing Statement}

The data of this study are available upon special request to the corresponding author.

\section{Ethics Approval and Consent Statement}

This study was conducted in accordance with the World Medical Association Declaration of Helsinki and was approved by the Medical Ethics Committee of the First Affiliated Hospital of Chongqing Medical University (2021021).

\section{Consent for Publication}

Patients signed informed consent regarding publishing their data and photographs.

\section{Acknowledgments}

The authors are grateful to all the colleagues who helped in the preparation of this article.

\section{Author Contributions}

All authors made substantial contributions to conception and design, acquisition of data, or analysis and interpretation of data; took part in drafting the article or revising it critically for important intellectual content; agreed to submit to the current journal; gave final approval for the version to be published; and agreed to be accountable for all aspects of the work.

\section{Funding}

There is no funding to report.

\section{Disclosure}

The authors declare that they have no competing interests.

\section{References}

1. Bray F, Ferlay J, Soerjomataram I, Siegel RL, Torre LA, Jemal A. Global cancer statistics 2018: GLOBOCAN estimates of incidence and mortality worldwide for 36 cancers in 185 countries. CA Cancer J Clin. 2018;68(6):394-424. doi:10.3322/caac.21492

2. Zhou C, Hu J, Wang Y, et al. A machine learning-based predictor for the identification of the recurrence of patients with gastric cancer after operation. Sci Rep. 2021;11(1):1571. doi:10.1038/s41598-021-81188-6

3. Zhang N, Deng J, Wang W, et al. Negative lymph node count as an independent prognostic factor in stage III patients after curative gastrectomy: a retrospective cohort study based on a multicenter database. Int J Surg. 2020;74:44-52. doi:10.1016/j.ijsu.2019.12.018

4. Min SH, Won Y, Kim G, et al. 15-year experience of laparoscopic gastrectomy in advanced gastric cancer: analysis on short-term and long-term oncologic outcome. Surg Endosc. 2020;34(11):4983-4990. doi:10.1007/s00464-019-07292-x
5. Sierzega M, Kolodziejczyk P, Kulig J; Polish Gastric Cancer Study Group. Impact of anastomotic leakage on long-term survival after total gastrectomy for carcinoma of the stomach. Br J Surg. 2010;97 (7):1035-1042. doi:10.1002/bjs.7038

6. Andreou A, Biebl M, Dadras M, et al. Anastomotic leak predicts diminished long-term survival after resection for gastric and esophageal cancer. Surgery. 2016;160(1):191-203. doi:10.1016/j. surg.2016.02.020

7. Yuan $\mathrm{P}, \mathrm{Wu} \mathrm{Z}, \mathrm{Li} \mathrm{Z}$, et al. Impact of postoperative major complications on long-term survival after radical resection of gastric cancer. BMC Cancer. 2019;19(1):833. doi:10.1186/s12885-019-6024-3

8. Zheng ZF, Lu J, Zhang PY, et al. Novel abdominal negative pressure lavage-drainage system for anastomotic leakage after R0 resection for gastric cancer. World $J$ Gastroenterol. 2019;25(2):258-268. doi:10.3748/wjg.v25.i2.258

9. Inokuchi M, Otsuki S, Fujimori Y, Sato Y, Nakagawa M, Kojima K. Systematic review of anastomotic complications of esophagojejunostomy after laparoscopic total gastrectomy. World J Gastroenterol. 2015;21(32):9656-9665. doi:10.3748/wjg.v21.i32.9656

10. Selby LV, Vertosick EA, Sjoberg DD, et al. Morbidity after total gastrectomy: analysis of 238 Patients. J Am Coll Surg. 2015;220 (5):863-871.e2. doi:10.1016/j.jamcollsurg.2015.01.058

11. Lang H, Piso P, Stukenborg C, Raab R, Jähne J. Management and results of proximal anastomotic leaks in a series of 1114 total gastrectomies for gastric carcinoma. Eur J Surg Oncol. 2000;26 (2):168-171. doi:10.1053/ejso.1999.0764

12. Yoo HM, Lee HH, Shim JH, Jeon HM, Park CH, Song KY. Negative impact of leakage on survival of patients undergoing curative resection for advanced gastric cancer. $J$ Surg Oncol. 2011;104(7):734-740. doi: $10.1002 /$ jso. 22045

13. van Rossum PSN, Haverkamp L, Verkooijen HM, van Leeuwen MS, van Hillegersberg R, Ruurda JP. Calcification of arteries supplying the gastric tube: a new risk factor for anastomotic leakage after esophageal surgery. Radiology. 2015;274(1):124-132. doi:10.1148/ radiol.14140410

14. Shen Z, An Y, Shi Y, et al. The Aortic Calcification Index is a risk factor associated with anastomotic leakage after anterior resection of rectal cancer. Colorectal Dis. 2019;21(12):1397-1404. doi:10.1111/ codi. 14795

15. Japanese Gastric Cancer Association. Japanese gastric cancer treatment guidelines 2010 (ver. 3). Gastric Cancer. 2011;14(2):113-123. doi:10.1007/s10120-011-0042-4

16. Dindo D, Demartines N, Clavien PA. Classification of surgical complications: a new proposal with evaluation in a cohort of 6336 patients and results of a survey. Ann Surg. 2004;240:205-213. doi:10.1097/01.sla.0000133083.54934.ae

17. Mori M, Shuto K, Hirano A, et al. A novel parameter identified using indocyanine green fluorescence angiography may contribute to predicting anastomotic leakage in gastric cancer surgery. World J Surg. 2020;44(8):2699-2708. doi:10.1007/s00268-020-05488-0

18. Nomura S, Sasako M, Katai H, Sano T, Maruyama K. Decreasing complication rates with stapled esophagojejunostomy following a learning curve. Gastric Cancer. 2000;3(2):97-101. doi:10.1007/ PL00011703

19. Deguchi Y, Fukagawa T, Morita S, Ohashi M, Saka M, Katai H. Identification of risk factors for esophagojejunal anastomotic leakage after gastric surgery. World J Surg. 2012;36(7):1617-1622. doi:10.1007/s00268-012-1559-3

20. Roh CK, Choi S, Seo WJ, et al. Incidence and treatment outcomes of leakage after gastrectomy for gastric cancer: experience of 14,075 patients from a large volume centre. Eur J Surg Oncol. 2021;S07487983(21):9-104.

21. Ichikawa D, Kurioka H, Yamaguchi T, et al. Postoperative complications following gastrectomy for gastric cancer during the last decade. Hepatogastroenterology. 2004;51:613-617. 
22. Migita K, Takayama T, Matsumoto S, et al. Risk factors for esophagojejunal anastomotic leakage after elective gastrectomy for gastric cancer. J Gastrointest Surg. 1659;2012(16).

23. Schietroma M, Cecilia EM, Carlei F, et al. Prevention of anastomotic leakage after total gastrectomy with perioperative supplemental oxygen administration: a prospective randomized, double-blind, controlled, single-center trial. Ann Surg Oncol. 2013;20(5):1584-1590. doi:10.1245/s10434-012-2714-7

24. Chuang ML, Massaro JM, Levitzky YS, et al. Prevalence and distribution of abdominal aortic calcium by gender and age group in a community-based cohort (from the Framingham heart study). Am J Cardiol. 2012;110(6):891-896. doi:10.1016/j.amjcard.2012.05.020

25. O’Connor SD, Graffy PM, Zea R, et al. Does nonenhanced CT-based quantification of abdominal aortic calcification outperform the Framingham risk score in predicting cardiovascular events in asymptomatic adults? Radiology. 2019;290:108-115. doi:10.1148/ radiol.2018180562
26. Nachiappan S, Askari A, Currie A, Kennedy RH, Faiz O. Intraoperative assessment of colorectal anastomotic integrity: a systematic review. Surg Endosc. 2014;28(9):2513-2530. doi:10.1007/s00464-014-3520-z

27. Karliczek A, Harlaar NJ, Zeebregts CJ, Wiggers T, Baas PC, van Dam GM. Surgeons lack predictive accuracy for anastomotic leakage in gastrointestinal surgery. Int J Colorectal Dis. 2009;24(5):569-576. doi:10.1007/s00384-009-0658-6

28. Trastulli S, Munzi G, Desiderio J. et al. Indocyanine green fluorescence angiography versus standard intraoperative methods for prevention of anastomotic leak in colorectal surgery: meta-analysis. $\mathrm{Br}$ J Surg;2021. znaa139. doi: 10.1093/bjs/znaa139

\section{Publish your work in this journal}

Cancer Management and Research is an international, peer-reviewed open access journal focusing on cancer research and the optimal use of preventative and integrated treatment interventions to achieve improved outcomes, enhanced survival and quality of life for the cancer patient.
The manuscript management system is completely online and includes a very quick and fair peer-review system, which is all easy to use. Visit http://www.dovepress.com/testimonials.php to read real quotes from published authors. 